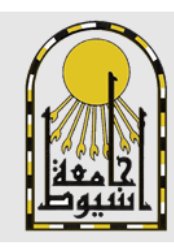

Journal of Engineering Sciences

Faculty of Engineering Assiut University

\title{
Effect of the Positioning of Multiple Charging Stations for Electric Vehicles on Grid Performance in Saudi Arabia: The Case of Jeddah City
}

\author{
Received 9 December 2021; Revised 8 January 2022; Accepted 19 January 2022
}

\author{
Mohammed Alqarni ${ }^{1}$
}

Keywords

Electric Vehicle

Vehicle to Grid (V2G)

EV charging station

\begin{abstract}
Electric vehicles (EV) have several advantages over traditional internal combustion vehicles, including lower local pollution, increased energy efficiency, and reduced reliance on oil. However, in many countries, such as Saudi Arabia (SA), considerable impediments to EV exist, including a lack of charging stations. What will happen as the future government strategy is to add a large number of charging stations in this country, and what effect will this have on the grid, particularly during the charging phase? The purpose of this research is to determine the power grid's capability in Saudi Arabia to house extra demand for EV charging. This research should aid in maintaining system stability and better planning for the future EV charging infrastructure. This paper aims to outline the effect of charging EVs on the grid and predict the possible number of charging stations that can be installed for a shopping mall parking space in Jeddah city. The data were collected from daily energy consumption and energy peak demand records from a shopping mall substation, and a total of eight EV charging scenarios were simulated. The load profile was analysed for all scenarios, and as a result, $100 \%$ and $41 \%$ charging capacities are recommended for slow and fast charging methods, respectively.
\end{abstract}

\section{Introduction}

Today, several suggested alternatives to fossil fuels are under investigation to replace fossil fuels in many applications affecting human life and industries. Several economic and political ambitions lie behind this replacement, one of which is to control greenhouse gas pollution, which leads to global warming [1]. One of the affected aspects of this issue is the transportation sector, and the solution is to completely move to electrification by replacing many conventional transport vehicles based on the internal combustion engine with electric traction systems [2].

\footnotetext{
${ }^{1}$ Electrical Engineering Dept., College of Engineering, University of Business and Technology (UBT), Saudi Arabia
} 
These electrified transportation systems are widely utilized throughout the world, particularly in Asia and Europe. The number of electric vehicles (EVs) around the world in 2017 was 3 million vehicles, while in 2018, the number increased up to 5.1 million vehicles, an increase of 2 million vehicles in only one year [3]. This rapid increase in the number of EVs worldwide requires the establishment of an infrastructure for charging stations.

Despite the benefits that these new transportation tools provide, some problems and vulnerabilities have emerged, posing additional challenges to the user. The first disadvantage is that these transportation technologies have limited range. The maximum supported range has surpassed 700 kilometers without the requirement for recharging. This type of system has a high cost, and few such electric car models are available. The most common versions have a maximum range of 350 kilometers, requiring recharging multiple times every day. This necessitates the installation of multiple recharge stations in various locations around cities, such as near highways, at traditional gas stations, and in the home. Even with the complexity of this recharging system and the accompanying requirements and normalization that must be met, an indirect problem arises when these recharge stations are connected to the grid for power [4-5]. As a result, an increase in the number of EVs will be inextricably linked to an increase in power demand in certain areas, whether that area is as small as a residential neighborhood or as large as a country [6]. The behavior of charging is also critical in ascertaining whether the increasing demand is controllable or not. As suggested in the literature, many recharge methods exist, but basically, two categories are present: the grid-to-vehicle $(\mathrm{G} 2 \mathrm{~V})$ recharge system and the autonomous recharge method. The latter category is used for hybrid cars (HEV), cars based on photovoltaic panels (PVEV), or vehicle-to-vehicle (V2V) technology. Wireless recharge technology can be classified in the G2V category, as the main energy source comes from the grid [1] .

Referring to the majority of cited references including discussions of the recharge tools used for specific kinds of electric cars, the G2V solution seems the most used and dominant [8]. The inductive power transfer recharge tool can also be classified as a G2V tool, as the transmitter is connected to the grid via a series of converters. The paper cited in [9] gives a clear view of multiple recharge systems and classifies G2V as a useful solution. The G2V recharge tool can be used in the home or at recharge stations, and the energy can be obtained from the grid. If concentrating on road recharge or parking recharge stations, many difficulties appear for stratifying the overall process. Actually, these recharge stations can be connected to the grid side via a series of power transformers, and the energy load line (source, transformers, the recharge station, and vehicle) must be correctly designed to avoid any problems with shutdowns on the energy production line [10-11]. The majority of installations must be correctly designed (with correct calculations and dimensions), including the energy distributed line, before any additional load can be added. Each part must be evaluated properly. Therefore, one of this paper's objectives is to present a useful method for determining whether to add recharge stations that are connected to distributed energy lines. However, an alternative solution is photovoltaics-where distributed lines exist and cannot be extended. Photovoltaics can resolve such problems for some isolated stations, as in the case studied in [12].

Focusing on the most often utilized recharge technique, the G2V method, this study provides an examination of the impact of increasing the number of EVs in Saudi Arabia, as well as the number of recharge stations that will be connected to the electrical grid. The additional charge that needs to be applied to the electric grid is discussed in regard to the best combinations that can assure grid stability and avoid shutdowns. This study was conducted on the largest shopping mall in Jeddah City, which offers more than 1500 
parking spaces and attracts more than 22 million visitors annually [13]. This research aims to evaluate the utilization of approximately 100 electric cars and 1000 electrical charging stations. The evaluation of this large number of electrical charger stations on the grid was devised under four different charging scenarios. In this study, these scenarios are separately tested, and statistics related to charger methods (the slow method and high-speed rechargers) are provided. The obtained results and statistics should help policy makers understand the extent to which the existing distribution stations are appropriate and the extent of the need for new infrastructure.

This work is described in five principal parts. After the introduction, section II deals with the state of the art in regard to possible electrical vehicle designs and their recharge methods and concepts. Section III offers a discussion of the wired charger model and its functioning principle. Section IV presents an analysis of the impact of adding 150, 250, 500, and 1000 vehicle chargers on the grid. Section V gives recommendations for the studied zone, the needed number of new transformers, and the possible number of vehicles that can be connected to the existing grid. Finally, Section VI offers a summary of the outcomes.

\section{Electric vehicle and charging types}

\subsection{Electric vehicle models}

EVs are spreading around the world at a fast rate due to the evolution of technology, which has helped manufacturers improve the capacities of batteries in these cars [4]. Moreover, EVs are improving every day due to new designs, concepts, control methods, energy management applications, and useful solutions for quick recharging. These electrified transportation systems can be classified into two basic models: the pure electric vehicle, which uses only electrical energy for feeding the vehicle, and the hybrid electric vehicle, which uses more than one energy source to provide the necessary power.

Researchers suggest that there are four types of EVs [4, 14]. The first type, the whole battery EV (BEV), uses powerful and efficient batteries that can generate electricity to spin the wheels. Because of the storage systems for these cars, it takes a long time to recharge the batteries. The most used battery model is the Li-ion battery due to its efficiency. Li-ion batteries convert chemical energy to electrical energy and are expected to dominate the market due to their long-life cycles and low self-discharging losses. However, one of the disadvantages of Li-ion batteries is that they are sensitive to overcharging, so they demand a high-quality management system [3]. The second type, the hybrid EV (HEV), has two motors: one is electric, and the other is an internal fuel-fired combustion engine. The car is energized by the electric-powered electric motor, while the internal combustion engine burns fuel to intermittently charge the batteries [4].

The third type, the plug-in hybrid EV (PHEV), has both a combustion engine and an electric motor with a high-energy battery. PHEVs control which engine to use depending on the speed of the car. For example, the new Lexus ES has a hybrid engine that uses the electric motor until it reaches $80 \mathrm{~km} / \mathrm{h}$; after exceeding this speed, the combustion engine begins working because of the power required by the car to spin the wheels [4]. The fourth type, the hydrogen fuel cell EV (HFCEV), utilizes hydrogen and air to generate electricity and power the car. The fuel cell directly powers the electric motor and can recharge the battery pack, if necessary, by capturing the energy generated by the braking system while the fuel cell is warming up [7]. Figure 1 summarizes the differences between the models. 


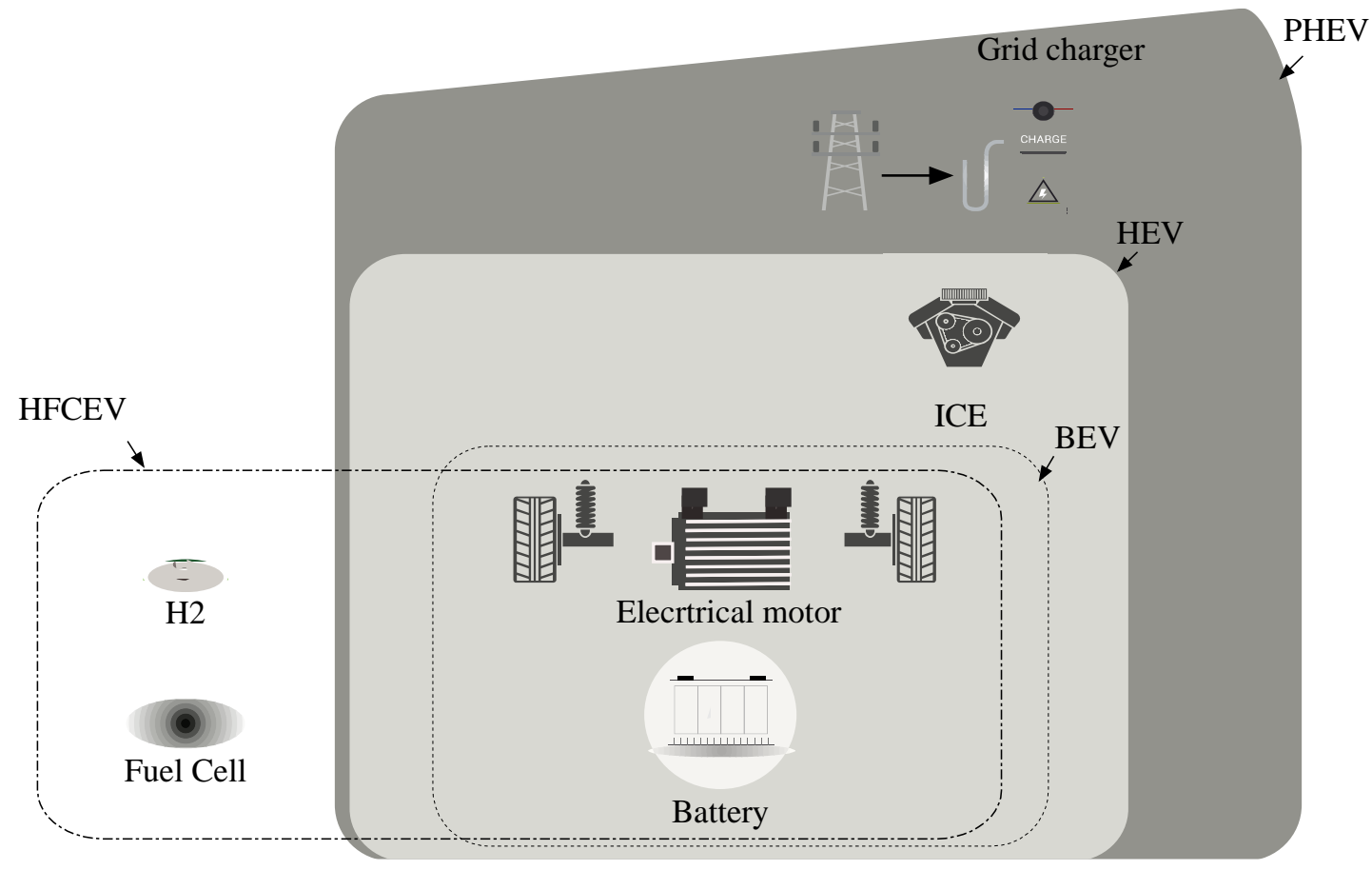

Fig1. Various EV architectures

\subsection{EV charging systems: different models and modes}

Depending on the charging time available, chargers can be installed in houses, offices, shopping malls, and public places to enable EV owners to charge their cars. The charging time is determined by the following equation (1). The given power of the charger has an important role in regard to the acceleration of the recharge phase. If the charger has greater power, the recharge will be quicker. $T_{r}$ is the needed recharge time for charging a battery [5].

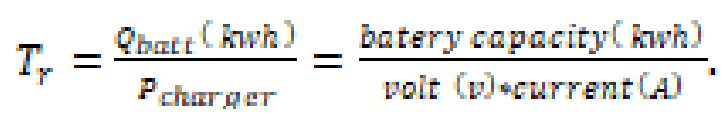

Various recharge tools exist, and two categories can be cited. The first is the wired charger, and the second is the wireless recharge tool.

\subsubsection{Wired recharging tool}

The wired type of charger simply involves connecting the EV to an electricity outlet using a proper interface and conductors. The corresponding charging structure is shown in Figure 2. In this category of wired chargers, four modes exist, and their specifications are summarized in Table 1:

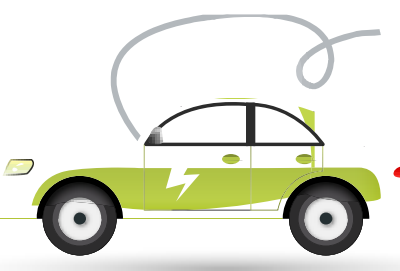

$\mathrm{G} 2$

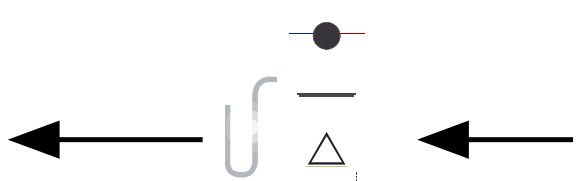

charger

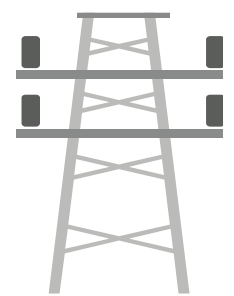

Grid

Fig2. Wired charging [11] 
Mode 1: This model is based on a standard AC voltage of $230 \mathrm{~V}$ for Europe and most of the world and $110 \mathrm{~V}$ in the United States, with a maximum of $16 \mathrm{~A}$ household power plugs. As this model supplies AC voltage, the EV is equipped with power electronic circuits to facilitate the DC charging process. The mode is considered the slowest among all other charging models, but it is cheap and convenient. Usually, an empty battery would need 7 15 hours to be fully charged [4, 15-16].

Mode 2: This is also an AC mode but with a maximum current of 32A. A voltage of either $230 \mathrm{~V}$ or $440 \mathrm{~V}$ is required. This type of charger is obtainable in public parking spaces within the city and around shopping malls, business parks, and so on. Finally, the charging time is between 3 and 8 hours [4, 15-16].

Mode 3: This case uses a three-phase-440V supply and is the fastest and most powerful type of AC charging available. The needed time for charging a vehicle is less than an hour, which makes it a suitable method to charge large vehicles and busses. Such charging poles exists in commercial areas and public bus stations [4, 15-16].

Mode 4: This charging mode is based on DC voltage and is significantly quick, with a current of up to 400A. However, the plug types must match the vehicle outlet. This mode dominates all other methods with a charge time of less than 30 minutes $[4,15-16]$.

Table 1: Summary of EV Charging Modes

\begin{tabular}{|c|c|c|c|}
\hline Modes & Source specifications & Time of full charge & Possible Location \\
\hline Mode (1) & $\begin{array}{c}\text { AC } \\
110 \mathrm{~V}-220 \mathrm{~V} \\
16 \mathrm{~A}\end{array}$ & $7-17$ hours & $\begin{array}{c}\text { Home } \\
\text { Office }\end{array}$ \\
\hline Mode (2) & $\mathrm{AC}$ & & Public places \\
& $\begin{array}{c}220 \mathrm{~V}-440 \mathrm{~V} \\
32 \mathrm{~A}\end{array}$ & $3-8$ hours & Charging stations \\
\hline Mode (3) & $\mathrm{AC}$ \\
& $640 \mathrm{~A}$ & Less than 1 hour & Charging stations \\
\hline Mode (4) & DC fast charging up to 400A & Less than 30 minutes & . \\
\hline
\end{tabular}

\subsubsection{Wireless recharging tool}

Wireless charging is now one of the simplest ways of charging an electric device, since there is not any wired connection between the charger and the device, which makes it easier to receive energy from the power source. Significant research is being done on wireless charging concepts, such as how to improve its efficiency, lengthen the distance between the transmitter and the receiver, and increase the charging range [6, 15, 17-19]. Moving on to the ways of charging EVs using a wireless power transfer, two options are available. The first method is magnetic resonance coupling, and the other method is inductive coupling [6]. Both resonant coils have to be working at the same frequency, and they have to be strongly coupled to gain high efficiency in the power transfer. When designed properly, magnetic resonance coupling can attain a high efficiency rate of up to $92.6 \%$ over a distance of $0.3 \mathrm{~cm}$ [5]. Another advantage of this method is that one transmitter has the ability to distribute energy to multiple receivers. The range of transmitting energy distance is from centimeters to meters; however, efficiency decreases as the distance rises. Finally, the frequency has to be in the megahertz range $(3-30 \mathrm{MHz})$ to operate charging [6]. Inductive coupling depends on the principle of magnetic field induction, which transfers energy from a primary coil to a secondary coil. This method involves a short-range wireless power transfer that ranges from a few millimeters to a few centimeters [6]. The frequency of inductive coupling, which 
ranges from $3 \mathrm{kHz}$ to $300 \mathrm{kHz}$, is considered small compared to the magnetic resonance frequency [19]. One of the advantages of inductive coupling is the capability of transferring power in the kilowatt range [6]. Figure 3 shows a wireless charger design. Some researchers have classified the inductive coupling-based recharge technology as a G2V recharge tool. This is correct, as the first element (the transmitter) is connected to the grid. More information can be found in [20].

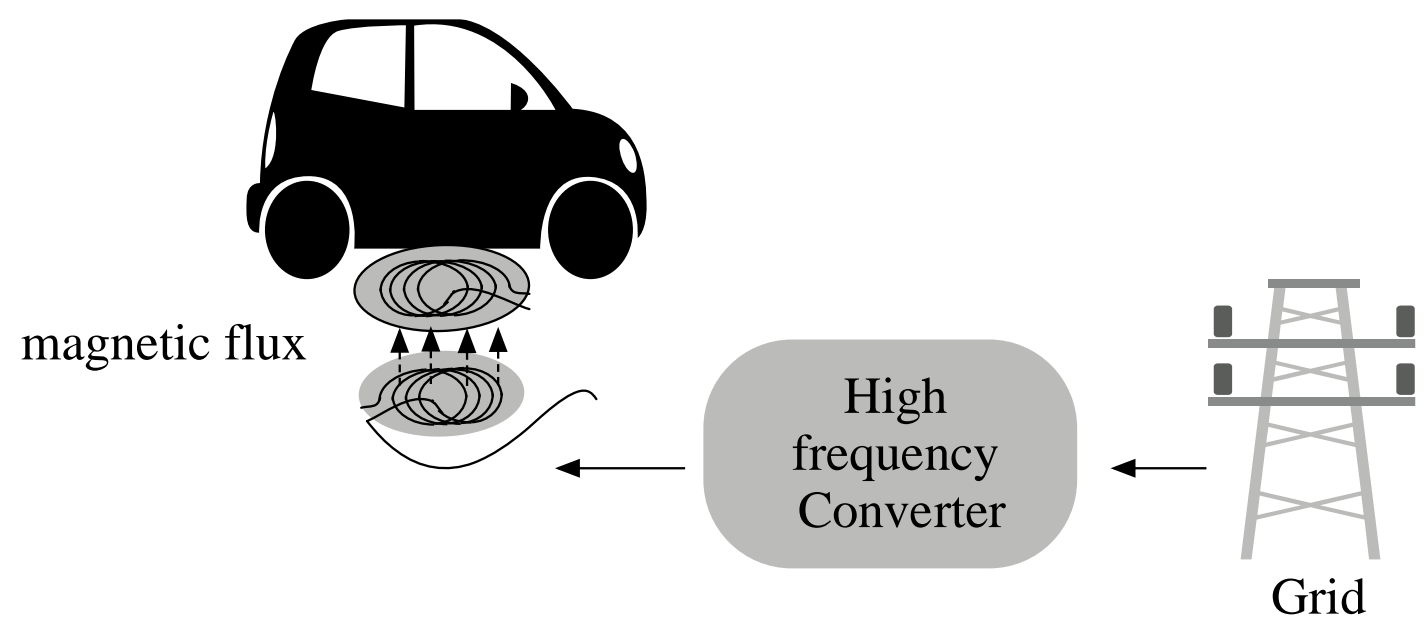

Fig3. Wireless charging [11]

\section{Wired charger type: specifications of vehicle-to-grid stations}

A study in 2013 showed that the amount of load peak consumed in Los Angeles by EVs is approximately 6\% [21-22]. Another study conducted in the UK predicted the EV demand would hit $20 \mathrm{GW}$ by 2035 [21]. Many researchers have attempted to predict the future grid behavior with the expected high penetration of EVs. These studies have focused on the impacts of EV charging on the grid, such as reductions in power levels, voltage drops, system losses, and power quality, and some researchers have discussed some alternatives solutions to mitigate those impacts [21] [27] [25] The expected increased demand on the power grid due to the penetration of EV charging has encouraged the introduction of a new model called vehicle-to-grid (V2G) charging. This model performs four main functionalities regarding the power grid: valley filling, peak shaving, regulating frequency, and spinning reserve [14]

- Valley filling involves charging at off-peak times when the load on the power grid is at a minimum [14]

- Peak shaving is the opposite of valley filling, where peak demand EVs support the grid by discharging [14]

- In frequency regulation, EVs act as a large storage system that can help increase the frequency when it drops due to high demand and vice versa.

- Spinning reserve involves an emergency amount of power that can be injected into the grid in the case of unplanned events. The supply lasts for a certain amount of time until power is restored [14] For example, in the United States in 2007, the minimum duration for this reserve was 5 minutes, while the maximum duration was 51 minutes [27] 


\section{Impact of the new recharge station on the Saudi grid}

\subsection{Specifications of the Saudi grid}

A study about the power sector of Saudi Arabia [25] was conducted in 2017 by the Electricity and Cogeneration Regulatory Authority (ECRA) that revealed the total electricity generation and consumption in the country. According to the study, the total generation of Saudi Arabia was around 80 gigawatts, and its distribution all over the country was as follows: The Eastern region had an available generation capacity of $23 \mathrm{GW}$ with a peak load of $20 \mathrm{GW}$, which was considered the highest among all the regions due to the fact that most industrial sectors and manufacturing facilities are located there. The Central region had an available generation capacity of $16 \mathrm{GW}$ with a peak load of $20 \mathrm{GW}$, which is more than the available capacity because of the heavy population (over 10 million residents) concentrated there. The Western region had an available generation capacity of $21 \mathrm{GW}$, while the peak load achieved $19 \mathrm{GW}$. Finally, the Southern region had a generation capacity of $4 \mathrm{GW}$, and its peak load was 6 GW. The overall peak in Saudi Arabia in 2017 achieved 62 GW, which happened in the summer, whereas the winter peak load was about $35 \mathrm{GW}$ [25]

\subsection{Addition of $\mathrm{EV}$ recharge stations on the grid: the case of Jeddah city}

With the rapid increase in the number of EVs around the world in general and with the Kingdom of Saudi Arabia's ambitious plan to achieve $30 \%$ EV penetration in the car market by 2030 [28] the establishment of an infrastructure for charging stations is required. Therefore, the impact of adding 1000 recharge stations in Jeddah City is considered here. Basically, this study aims to solve the power shortage problem during peak hour demand and verify the potential of adding more recharge stations.

This study utilized the MATLAB/Simulink tool, in which the first goal was to analyze the EV charging impacts on the distribution grid. The simulations were done for a total of 15 MW generating power and for a 600V AC charger [21] .

With these charger specifications and assuming 100 vehicles connected to the charging stations, the energy that could be consumed would be around $4 \mathrm{MW}$ of power from the grid. Each couple of vehicles would increase the power demand by $0.05 \mathrm{MW}$. Table 2 shows the impact of adding 2 to 100 vehicles on power grid consumption. It is estimated that 100 vehicles would increase the load on the grid by $25.24 \%$.

Table 2: Comparison of grid power consumption before and after adding electric vehicles to the grid [21]

\begin{tabular}{|c|c|c|c|}
\hline EV number & Power before & Power after & Power increase \\
\hline 2 & $10.25 \mathrm{MW}$ & $10.30 \mathrm{MW}$ & $0.05 \mathrm{MW}$ \\
\hline 50 & $10.30 \mathrm{MW}$ & $11.40 \mathrm{MW}$ & $1.1 \mathrm{MW}$ \\
\hline 100 & $10.30 \mathrm{MW}$ & $12.90 \mathrm{MW}$ & $2.6 \mathrm{MW}$ \\
\hline \multicolumn{2}{|r}{ *Each car consumes 0.025 MW. The relationship is a linear function. } \\
\hline
\end{tabular}

Taking into consideration that these values depict the consumed power of each vehicle, we assume the placement of 1000 recharge connectors. A large business park with 1000 parking slots in Jeddah, Saudi Arabia, was evaluated, with each parking space having an EV recharge station (see the map in Fig. 5). The load values at the substation that feeds the business park were evaluated under two different charging types (slow and fast charging) and for the null state of charge of the vehicle when starting the recharge action. A strategic planning process was deployed in evaluating the additional load of EV penetration into the 
existing network. The recorded load data was obtained between 02/03/2019 and 24/02/2020. The total number of EV penetration was assumed to be 1000. Table 3 provides some statistics in regard to adding 150, 250, 500, or 1000 vehicles and presents the kind of power needed when the slow or fast charging methods are used.

Table 3: Various scenarios including developed load due to EV penetration percentage

\begin{tabular}{|c|c|c|c|c|}
\hline $\begin{array}{l}\text { Test } \\
\text { Case }\end{array}$ & $\begin{array}{c}\text { EV Penetration } \\
(\%)\end{array}$ & $\begin{array}{l}\text { Charging Type } \\
\text { (S/F) }\end{array}$ & $\begin{array}{l}\text { Load }(k V A) \text { due to } E V \\
\text { penetration }\left(L_{S} \text { and } L_{F}\right)\end{array}$ & $\begin{array}{c}\text { Total No. of EV } \\
\text { (Nv) }\end{array}$ \\
\hline 1 & 15 & $\begin{array}{l}\text { Slow } \\
\text { Fast }\end{array}$ & $\begin{array}{c}475 \\
1900 \\
\end{array}$ & 150 \\
\hline 2 & 25 & $\begin{array}{l}\text { Slow } \\
\text { Fast }\end{array}$ & $\begin{array}{c}792 \\
3168\end{array}$ & 250 \\
\hline 3 & 50 & $\begin{array}{l}\text { Slow } \\
\text { Fast }\end{array}$ & $\begin{array}{l}1584 \\
6336\end{array}$ & 500 \\
\hline 4 & 100 & $\begin{array}{l}\text { Slow } \\
\text { Fast }\end{array}$ & $\begin{array}{c}3168 \\
12672\end{array}$ & 1000 \\
\hline
\end{tabular}

In Table 3, the formulas for calculating the load $(\mathrm{kVA})$ due to EV penetration are as follows:

- For the slow recharge station, the load is evaluated as

$$
L_{S}=S . N_{v}
$$

- For the fast recharge station, the load is evaluated as

$$
L_{F}=F_{\mathrm{*}} \mathbb{N}_{\mathrm{v}^{x}}
$$

$\mathrm{S}$ and $\mathrm{F}$ are the slow and fast factors, respectively, equivalent to the demand power from the power transformer. $s=3.16 \mathrm{kVA}$ and $F=12.66 \mathrm{kVA}$. The grid installation is the studied zone, based on three transformers (as mentioned in Fig. 4). The first transformer, noted as Transformer 1, has $2500 \mathrm{kVA}$ as the possible rating power. The other two transformers each have a $2000 \mathrm{kVA}$ rating power. Each transformer can have 333 vehicles connected.

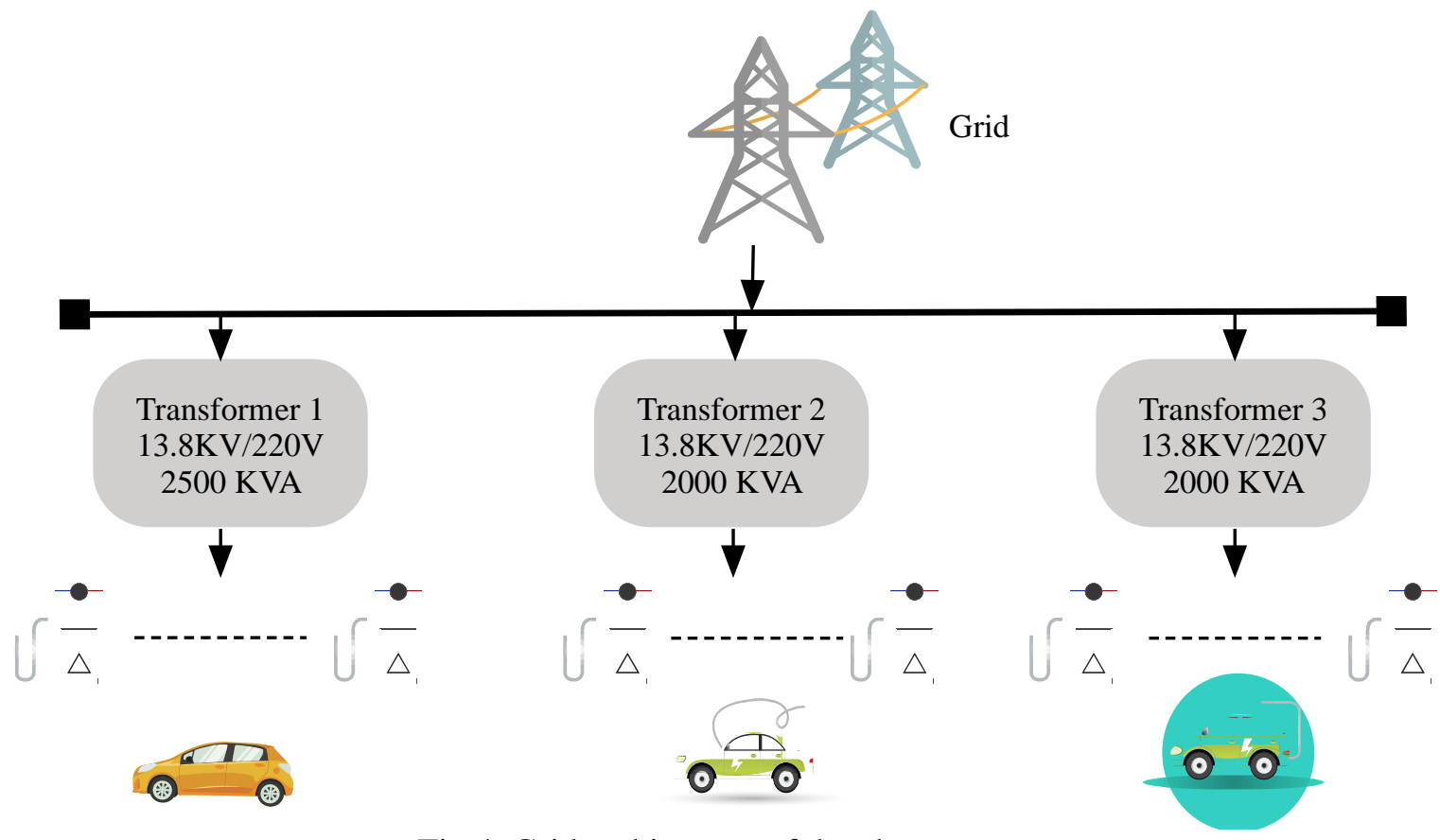

Fig 4. Grid architecture of the charger system 
Based on the capacity of the parking spaces of the business park [13], the substation was assumed to supply 1000 EVs. Four scenarios were applied to test the impact on the grid and on each of those transformers. Those scenarios were evaluated at the "Red Sea Mall," which is at "J4H6+2C Ash Shati, Jeddah" (see Fig. 5).

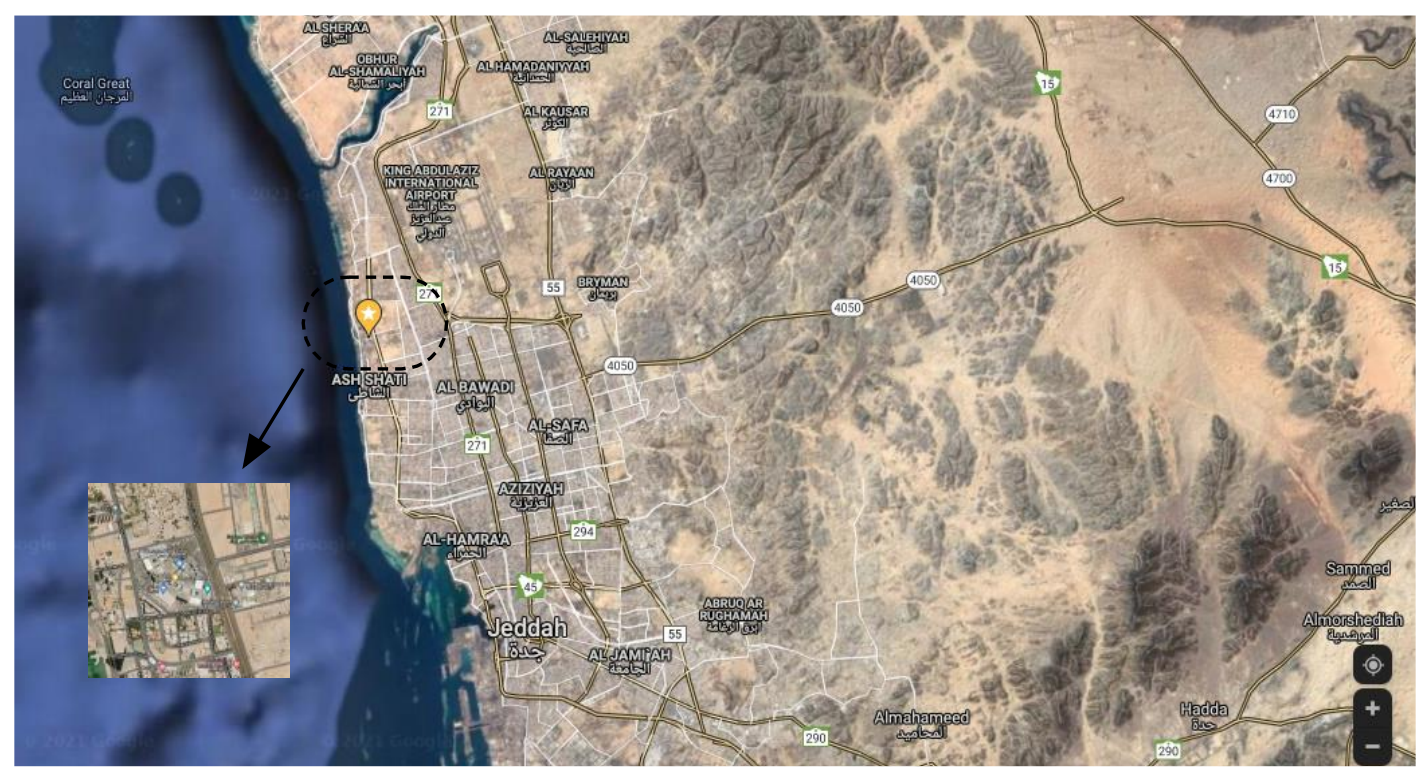

Fig 5. Studied zone

\subsubsection{Case 1: 15\% EV connected to slow and fast charging modes}

To monitor the loading status of each transformer in the substation, the total load for each scenario must be calculated as follows using Eq. (2) and Eq. (3) for slow and fast charging modes, respectively. The given statistics show that if 150 vehicles are connected to the charger, according to Eq. (2), the power supply will increase by $195.56 \mathrm{kVA}$ for each transformer when the slow charger is used. However, if the fast charger is used, the load of each transformer will increase by $782.22 \mathrm{kVA}$. All the statistics were applied for 50 vehicles on each transformer. Figure 6 shows that all the transformers work within their capacity whether the slow or fast charging method is adopted.

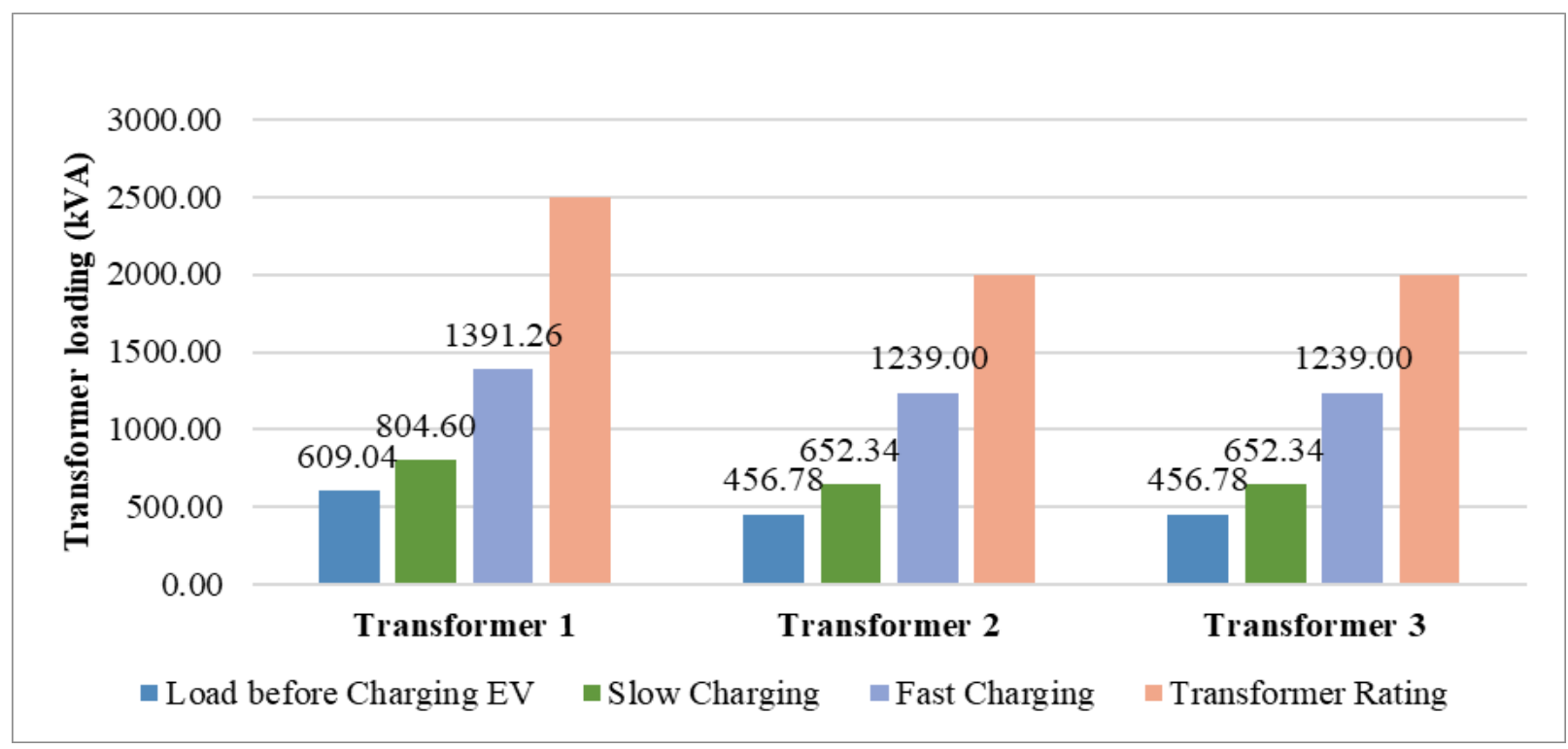

Figure 6. The case of 150 vehicles connected on the grid in slow/fast charging modes 


\subsubsection{Case 2: $25 \%$ EV connected in slow and fast charging modes}

This test case involves the connection of EVs to slow and fast charging outlets (Fig. 7), and $25 \%$ of the connected EVs act as a load for the substation in addition to the existing load. The first transformer charges 84 vehicles, and the other two transformers charge 83 vehicles each. The substation is loaded with an extra $973.86 \mathrm{kVA}$ of power to the existing load during slow charging. For the fast-charging EVs, 3.89 MVA of power is added to the substation.

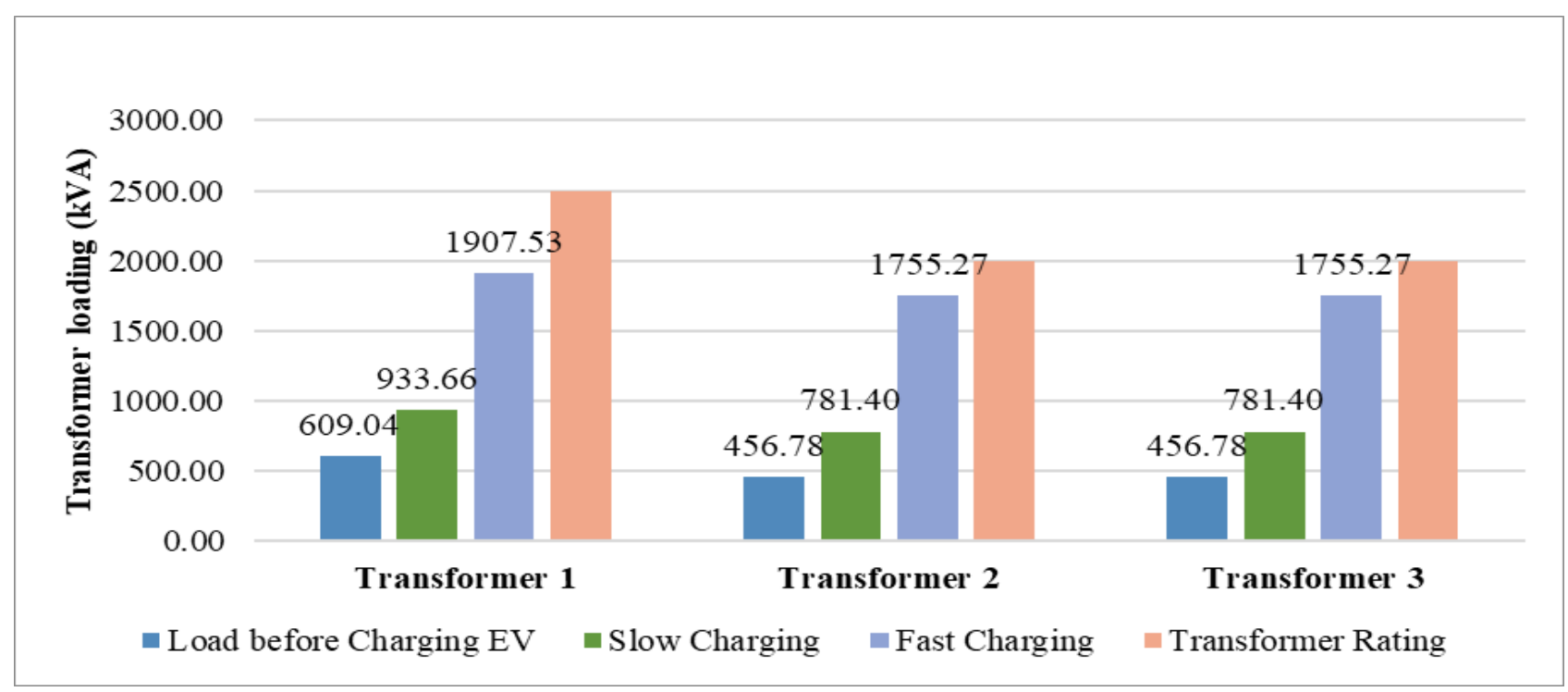

Figure 7. The case of 250 vehicles connected to the grid with slow/fast charging modes

During slow and fast charging, the substation is rated at 2.49 MVA and 5.4 MVA, which are below the rating limit of $6.5 \mathrm{MVA}$. Figure 7 shows the data for each transformer under this operating condition, with all the transformers comfortably handling the slow charging loads; however, transformers 2 and 3 operate near the margin at $88 \%$ of capacity when fast charging is adopted. These results prove that those transformers are remained within their power capabilities.

\subsubsection{Case 3: 50\% EV connected in slow and fast charging modes}

In this test case, the substation is loaded with 1.95 MVA to the existing load during slow charging. While fast charging the EVs, they will consume $7.83 \mathrm{MVA}$. The transformer loading results obtained on performing the simulations are illustrated in Figure 8.

During fast charging, the substation is loaded at 9.36 MVA, which significantly exceeded its rating limited at 6.5 MVA. The transformers at the substation in this case are overloaded by $144 \%$ of the substation capability, which makes it impossible to operate and risks the whole grid. However, all the transformers are capable of handling the slow charging with almost $50 \%$ spare capacity, as the orange column shows in Figure 8. 


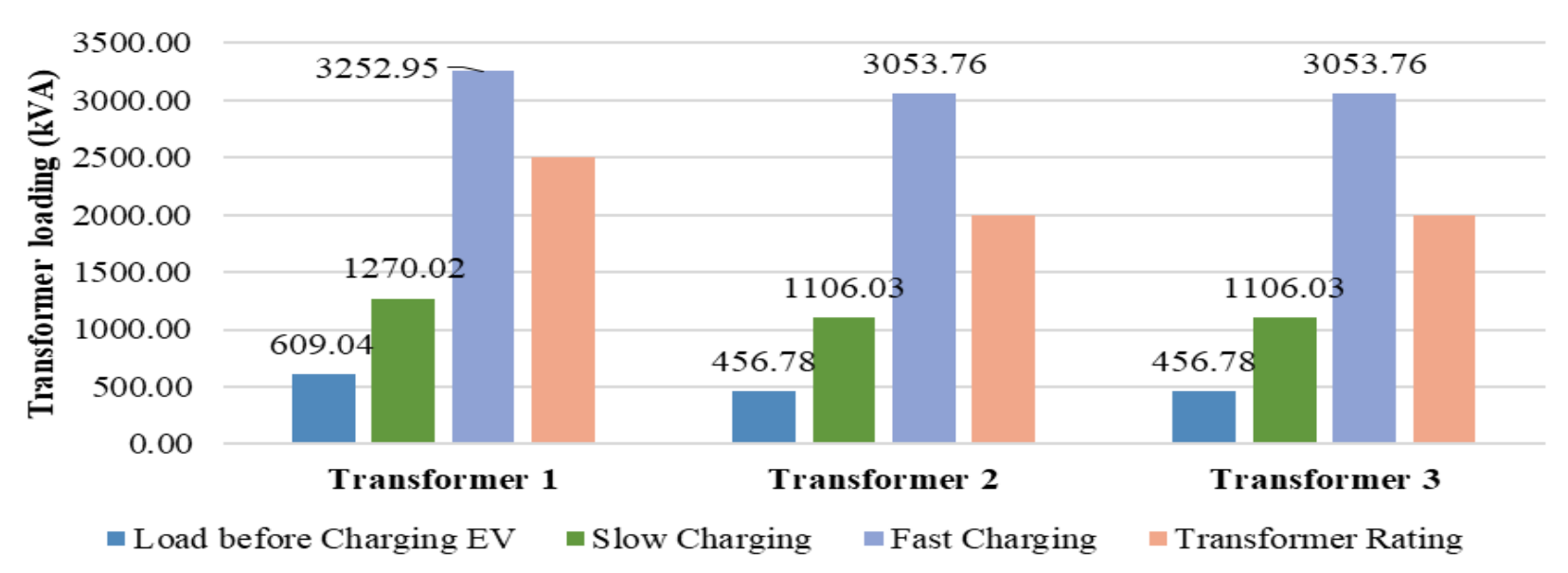

Figure 8. Transformer loading with 50\% EV penetration in slow/fast charging modes

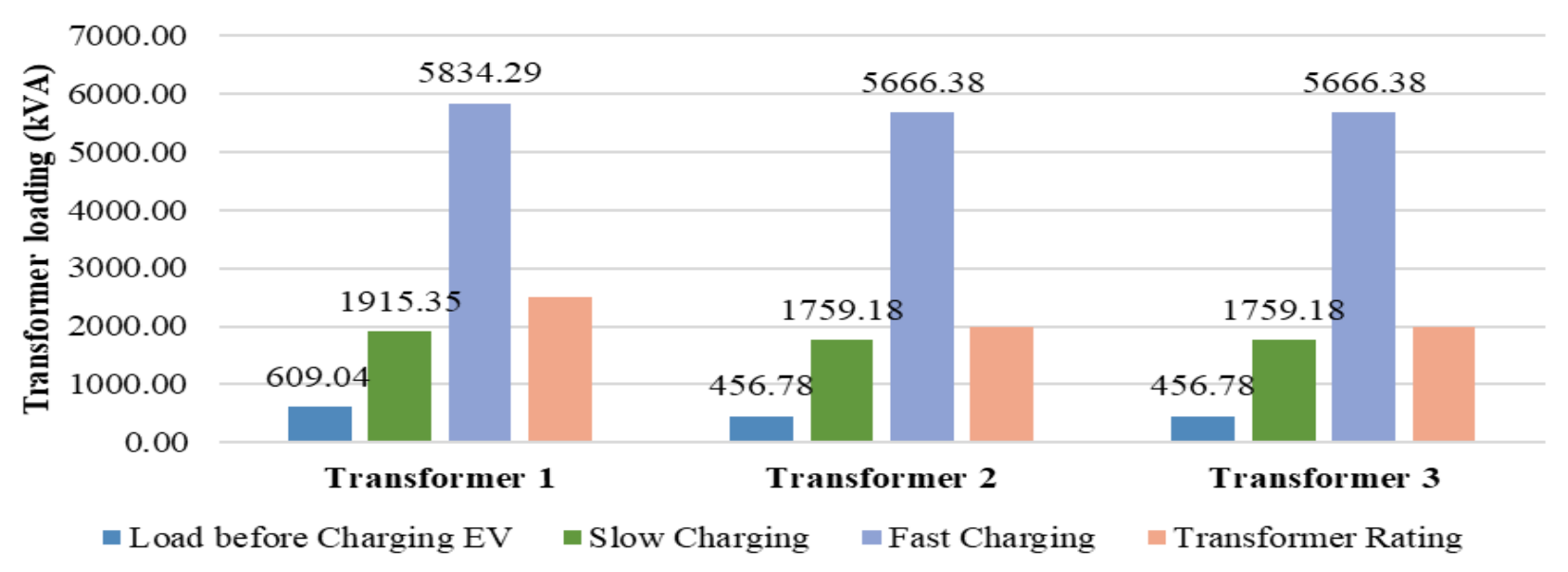

Figure 9. Transformer loading with $100 \% \mathrm{EV}$ penetration in slow/fast charging modes

\subsubsection{Case 4: $100 \%$ EV connected in slow and fast charging modes}

In this test case, the total capacity of the site is modeled to accommodate $1000 \mathrm{EVs}$ at the time of charging. The results are as illustrated in Figure 9. The substation can handle the slow charging modes for $1000 \mathrm{EVs}$ divided among the three transformers. However, fast charging infrastructure deployment at $100 \% \mathrm{EV}$ penetration on site is possible only if reinforcement of the transformer and cables takes place. The transformer is overloaded in this scenario. Therefore, the only solution is to reduce the vehicle numbers or to increase the number of transformers. Finally, the annual load that can be applied on the first transformer, taking into consideration the fast or the slow charger, can be visualized in Figure 10.

This result for the 1-year period from 3/2/2019 to 2/2/2020 shows that the problem appears when the fast charger is installed. For all the car numbers, slow charging can be safely used even if up to 1000 vehicles are connected. Figure 10 shows the statistics regarding the first transformer from $3 / 2 / 2019$ to $2 / 2 / 2020$. The given curves are related to the first transformer's given power for various conditions and the number of cars (charger stations) that can be connected. It indicates whether the slow or fast charger is used. The rated power for this transformer is $2500 \mathrm{kVA}$, and each curve under this reference enables the transformer to easily function. However, if the curve crosses this nominal value, the situation will be dangerous, and the transformer will be damaged. In this case, the fast recharge tool is used to power 169 vehicles. 


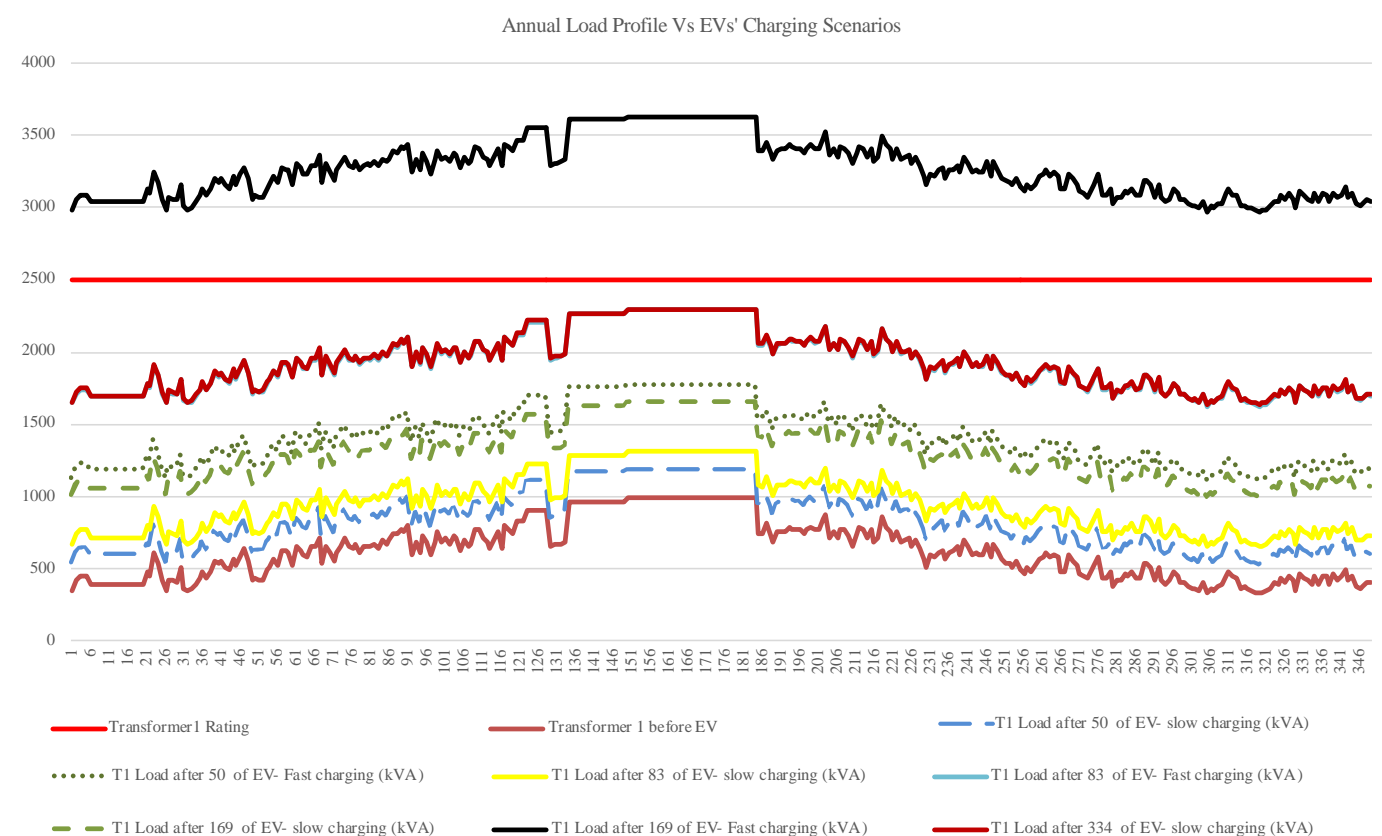

Fig10. Annual load of the first transformer when the fast or the slow charging method is used for the four studied cases

\section{Recommendation}

The possible vehicle numbers that can be charged together in the suggested site or the needed new transformers that must exist for having the capability of charging 1000 vehicles together are shown in Table 4.

Table 4: Possible combinations for the current and improved grid installation situations

\begin{tabular}{ccc}
\hline & $\begin{array}{c}\text { Number of possible chargers } \\
\text { for slow method }\end{array}$ & $\begin{array}{c}\text { Number of possible chargers } \\
\text { for fast method }\end{array}$ \\
\hline $\begin{array}{c}\text { Current situation } \\
(3 \text { transformers of } 6500 \mathrm{kVA})\end{array}$ & 1661 & 415 \\
\hline $\begin{array}{c}\text { Improved situation } \\
(7 \text { transformers of } 15850 \mathrm{kVA})\end{array}$ & 4502 & 1000 \\
\hline
\end{tabular}

With three $6500 \mathrm{kVA}$ transformers, it is possible to charge 1661 vehicles when the slow charger mode is selected. However, it is not possible to exceed 415 vehicles when the fast recharge mode is used. Therefore, the recommendation is to have 15,850 kVA of available power for fast charging 1000 vehicles. This will require adding four new power transformers to the site.

\section{Conclusions}

The aim of this work was to study the impact of EV charging on the Saudi Arabia grid. The studied case was in Jeddah City and was assumed to support 1000 chargers for EVs. Four scenarios were studied: the possibility of charging $150,250,500$, and 1000 vehicles with fast or slow charging methods. Three power transformers were used to feed those chargers, and the results showed that the examined power substation would be able to charge up to 1661 EVs with slow charging outlets and 415 EVs with fast charging outlets. If 1000 
chargers were installed, this would require $15850 \mathrm{kVA}$ of available power from a total of seven power transformers.

Even though the obtained results are satisfactory, this work is not without limitations, as all the calculations and statistics were based on suppositions about the vehicles, with an initial state of charge ratio equal to $0 \%$. In a real-world scenario, the batteries' power level would likely be at varies charging status. Therefore, the obtained power from the grid would be different and likely less than calculated in this research (for the same conditions of the application). Therefore, as a future endeavor, using different initial battery charge situations for the EVs could help predict the needed power for all cases. This could open the possibility of multiple research projects aimed to improve recharge management systems. It is possible to include a $5 \mathrm{G}$ communication tool to help predict the needed power for each vehicle and how the power could be managed on the grid from the source to the load.

\section{References}

[1] Rezaee, Saeed, Ebrahim Farjah, and Benyamin Khorramdel. "Probabilistic Analysis of Plug-In Electric Vehicles Impact on Electrical Grid through Homes and Parking Lots." IEEE Transactions on Sustainable Energy 4.4 (2013): 1024-1033. Print.

[2] Omar, Moien A., and Marwan M. Mahmoud. "Control of Power Converter Used for Electric Vehicle DC Charging Station with the Capability of Balancing Distribution Currents and Reactive Power Compensation." International Journal of Power Electronics and Drive Systems 12.2 (2021): 924. Print.

[3] Poullikkas, Andreas. "Sustainable Options for Electric Vehicle Technologies." Renewable and Sustainable Energy Reviews 41 (2015): 1277-1287. Print.

[4] Bhavanam, Yaminidhar Reddy. Combined Power System Planning and Policy Proposition for future Electric Vehicle Charging Infrastructure. Diss. Brunel University London, 2015. Print.

[5] Sheboniea, M. A., Mohamed. K. Darwish, and Al Janbey. "Impacts of Domestic Load and Electric Vehicles on Domestic Consumption in UK." 2016 51st International Universities Power Engineering Conference (Upec), IEEE, 2016.

[6] Adler, Martin W., Stefanie Peer, and Tanja Sinozic. "Autonomous, Connected, Electric Shared Vehicles (ACES) and Public Finance: An Explorative Analysis." Transportation Research Interdisciplinary Perspectives 2 (2019): 100038. Print.

[7] Burke, Andrew F. "Batteries and Ultra-Capacitors for Electric, Hybrid, and Fuel Cell Vehicles." Proceedings of the IEEE 95, 4 (2007): 806-820. Print.

[8] Hu, Xiaosong, Clara Marina Martinez, and Yalian Yang. "Charging, Power Management, and Battery Degradation Mitigation in Plug-In Hybrid Electric Vehicles: A Unified Cost-Optimal Approach." Mechanical Systems and Signal Processing 87 (2017): 4-16. Print.

[9] Aymen, Flah, et al. "Electric Vehicle Model Based on Multiple Recharge System and a Particular Traction Motor Conception." IEEE Access 9 (2021): 49308-49324. Print.

[10] Mwasilu, Francis, et al. "Electric Vehicles and Smart Grid Interaction: A Review on Vehicle to Grid and Renewable Energy Sources Integration." Renewable and Sustainable Energy Reviews 34 (2014): 501-516. Print.

[11] Alonso, Monica, et al. "Optimal Charging Scheduling of Electric Vehicles in Smart Grids by Heuristic Algorithms." Energies 7.4 (2014): 2449-2475. Print.

[12] Ahmad, Furkan, Mohd Khalid, and Bijaya Ketan Panigrahi. "An Enhanced Approach to Optimally Place the Solar Powered Electric Vehicle Charging Station in Distribution Network." Journal of Energy Storage 42 (2021): 103090. Print.

[13] Eyeofriyadh.com, "Red Sea Mall Launches 'Smart Parking' with 60 million Riyals", 2016. Web.

[14] Aslam, Maria. Vehicle to Grid Concept as Part of Power System and Electricity Market. MS thesis. Tampere University, 2017. Print. 
[15] Zhang, Wei, et al. "Loosely Coupled Transformer Structure and Interoperability Study for EV Wireless Charging Systems." IEEE Transactions on Power Electronics 30.11 (2015): 63566367. Print.

[16] Li, Xing, Chi-Ying Tsui, and Wing-Hung Ki. "A 13.56 MHz Wireless Power Transfer System with Reconfigurable Resonant Regulating Rectifier and Wireless Power Control for Implantable Medical Devices." IEEE Journal of Solid-State Circuits 50.4 (2015): 978-989. Print.

[17] Mude, Kishore Naik. "Battery Charging Method for Electric Vehicles: From Wired to OnRoad Wireless Charging." Chinese Journal of Electrical Engineering 4.4 (2018): 1-15. Print.

[18] Lu, Xiao, et al. "Wireless Charging Technologies: Fundamentals, Standards, and Network Applications." IEEE Communications Surveys \& Tutorials 18.2 (2015): 1413-1452. Print.

[19] Mohamed, Naoui, et al. "A New Wireless Charging System for Electric Vehicles Using Two Receiver Coils." Ain Shams Engineering Journal,13.2 (2021). Print.

[20] Mohamed, Naoui, Flah Aymen, and Mohammed Alqarni. "Inductive Power Transmission System for Electric Car Charging Phase: Modeling plus Frequency Analysis." World Electric Vehicle Journal 12.4 (2021): 267. Print.

[21] International Energy Agency (IEA), Global EV Outlook 2019, Paris, France.

[22] Haque, N., \& Saleque, A. M. "Impacts of Electric Vehicle Charging on Distribution Grid." AIUB Journal of Science and Engineering (AJSE), 18.3 (2019): 88-96. Print.

[23] Di Paolo, Marcelo. "Analysis of Harmonic Impact of Electric Vehicle Charging on the Electric Power Grid, Based on Smart Grid Regional Demonstration Project—Los Angeles." 2017 IEEE Green Energy and Smart Systems Conference (IGESSC). IEEE, 2017.

[24] Zamani, Muhammad Qusyairi Iqbal Mohd, Rahimi Baharom, and Dalina Johari. "Conceptual Study on Grid-to-Vehicle (G2V) Wireless Power Transfer Using Single-Phase Matrix Converter." International Journal of Power Electronics and Drive Systems 10.3 (2019): 1382. Print.

[25] Wogan, David, Shreekar Pradhan, and Shahad Albardi. "GCC Energy System Overview2017." King Abdullah Petroleum Studies and Research Center: Riyadh, Saudi Arabia (2017). Print.

[26] Elshurafa, Amro M., and Nawaz Peerbocus. "Electric Vehicle Deployment and Carbon Emissions in Saudi Arabia: A Power System Perspective." The Electricity Journal 33.6 (2020): 106774. Print.

[27] Kempton, Willett, et al. "A Test of Vehicle-To-Grid (V2G) for Energy Storage and Frequency Regulation in the PJM System." Results from an Industry-University Research Partnership 32 (2008). Print.

[28] Vivian Nereim, "Saudi Arabia to Start Electric-Vehicle Push in Capital Riyadh", Bloomberg Green, 2021. Print. 


\section{تأثير أمكان محطات الثحن المتعدة للمركبات الكهربائية على أداء الثبكة في المملكة العربية السعودية: مدينة جدة دراسة حالة}

الملخص العربي

تتمتع المركبات الكهربائية (EV) بالعديد من المزايا مقارنة بمركبات الاحتراق الداخلي التقليدية، بما في نلك انخفاض انبعاثات التلوث وزيادة كفاءة الطاقة وتقليل الاعتماية على النفط. ومع نلك، فان العديد من البلدان، منل المملكة العربية السعودية، هناك عوائق كبيرة أمام استخدام المركبات الكهربائية في الوقت الراهن، بما في ظلك نقص محطات الثحن. وبحسب ما أعلن عن استر اتيجية الحكومة المستقبلية التي تتمنل في إضافة عدد كبير من محطات الثحن الكهربائية، فما هو تأثير نلك على الثنبكة الكهربائية، خاصة أثثاء مرحلة الثحن؟ الغرض من هذا البحث هو تحلبد قرة شبكة الطاقة الكهربائية في المملكة العربية السعودية على استيعاب الطلب الإضافي لثحن المركبات الكهربائية. يفترض أن يساعد هذا البحث في الحفاظ على استقرار النظام والتخطيط الأفضل للبنية التحنية لثحن المركبات الكهربائية في المستقبل. وتهف هذه الورقة إلى تحليد تأثير شحن المركبات الكهربائية على الثنبكة والتنبؤ بالعدد المحتمل لمطات الثحن التي بمكن تركيبها لمواقف السيار ات في مركز التسوق في مدينة جدة. تم جمع الييانات من الاستهلاك اليومي للطاقة وسجلات الطلب في ذروة الطاقة من محطة فرعية خاصة بمركز التسوق، وتمت محاكاة ثمانية سيناريوهات لثحن المركبات الكهربائية. تم تحليل ملف

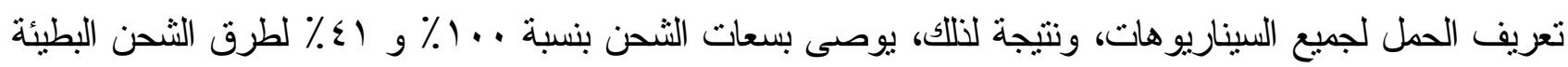
والسربعة، على التوالي. 